\title{
Heart, Aorta and Aortic Valve Development and Cardiovascular Malformations
}

\section{Salah A. Mohamed}

Department of Cardiac and Thoracic Vascular Surgery, University of Luebeck, Luebeck, Germany

*Corresponding author: Mohamed SA, Department of Cardiac and Thoracic Vascular Surgery, University of Luebeck, Luebeck, Germany, Tel: +49-451-50042352; Email: salah.mohamed@uksh.de

Received Date: May 18, 2017; Accepted Date: May 24, 2017; Published Date: May 31, 2017

Copyright: (C) 2017 Mohamed SA. This is an open-access article distributed under the terms of the Creative Commons Attribution License, which permits unrestricted use, distribution, and reproduction in any medium, provided the original author and source are credited.

\section{Introduction}

In vertebrates, the heart is the first organ to develop and takes shape during the third week of embryogenesis. The earliest evidence of a heart structure can be identified beginning from day 15 of pregnancy. Stem cells in the anterior-lateral mesoderm become specific cardiac precursor cells and align in a horseshoe shape. In the third week of pregnancy these heart precursor cells that are previously arranged in bilateral symmetrical manner move medially to unite and form a single primitive heart tube. This straight heart tube consists of an inner cell layer (endocardium), an outer cell layer (myocardium), and the extracellular matrix (ECM) separating the other two layers also known as the heart jelly.

The developmental stage that follows is a right-hand rotation of the heart leading to the first left-right non-symmetry in the embryo. Because of this rotation, the segments of the heart tube that later form the atria are positioned above the segment that forms the ventricles. The atria, ventricles, and truncus arteriosus originate through local extensions of the heart tube during heart loop shaping. Simultaneously, the ECM within the outflow tract and the future atrioventricular channel expand to form so-called endocardial cushions. Heart-tube segmentation into atria, ventricles, and the outflow tract is accomplished by these cushions. By further growth and additional fusions, they form septum- and valve-structure precursors, separating the developing ventricles from each other.

During the sixth and seventh week of pregnancy, the heart and the common outflow tract (truncus arteriosus) are chambered by the septa to divide into four distinct ventricles, the aorta, and the pulmonary artery. This results in the formation of a separate pulmonary and systemic circulation. The aorta and its respective segments originate from diverse embryonic structures. The ascending part of the aorta, the aorta ascenders is formed by the division of the truncus arteriosus as described above; however, the aortic arch and supra-aortic vessels originate from the third and fourth branchial arch arteries. The fivecomplete branchial arch artery pairs are also designated as aortic arches and originate from the truncus arteriosus, connecting it with the right and left dorsal aorta, which are also a part of the embryonic circulation. When the heart develops into the heart tube, valve morphogenesis also begins. The ECM in regions around the outflow tracts and between the atria and ventricles expand to form endocardial cushions, contributing to the formation of all four heart valves. During the next few days interactions between diverse endocardial and myocardial signals occur, which are of crucial importance for the transition remodeling of the endothelium and the mesenchyme. Following this transformation, mesenchymal cells proliferate and support further swelling of the endocardial cushions. In addition, myocardial cells infiltrate the edges of the endocardial cushions now containing mesenchymal cells [1-5].

In the truncus arteriosus, this growth of cushions supports the division of the outflow tract into the aorta and pulmonary artery and takes part in the formation of the aortic and pulmonary valves, each consisting of three leaflets. If during this stage of valvulogenesis, the original semilunar valve fails to separate and remain fused at the valve commissures; it results in the development of a bicuspid aortic valve $[2,6-9]$.

\section{Neural Crest Cells Influence the Heart Development}

Induced by growth factors, a bulge of the epithelial cluster, the neural plate, develops in the embryo's cranial region, in the ectoderm dorsal to the notochord. This plate's median groove is called the neural groove. Further proliferation of the neural plate's lateral edges results in the formation of neural folds, which fuse dorsomedial forming a tubular structure called as neural duct. Later, the central nervous system develops from the cephalic part of neural tube whereas the spinal cord develops from the caudal part.

The neural crest cells originate from the neural folds (the border region between the neurectoderm and the ectoderm) and are pluripotent and able to differentiate into many different cells such as melanocytes, nerve cells, connective tissue, and smooth muscle cells. These cells show high migratory activity on predefined tracks through the entire embryo. The cardiac neural crest cells originate from the most caudal part of the cranial neural crest located between the (midotic) placoderm and the third somite. They migrate via the pharyngeal arches III, IV, and VI, colonizing these as well as the aortic arches, the heart outflow tract, and the large proximal vessels. Influenced by the neural crest cells, the aortic arches undergo remodeling during development to finally form a part of the vessels mentioned above, such as the fourth branchial arch artery and the arcus aortae. Furthermore, the neural crest cells participate in the formation of the endocardial cushions within the truncus and the membrane sections of the interventricular septum. They also contribute to the septation and arrangement of the large vessels as well as the development of the semilunar valves. Studies using quailchicken chimera revealed that neural crest cells could be found in all three aortic and pulmonary valve leaflets [10].

\section{Bicuspid Aortic Valve and Other Genetically Inheritable Cardiovascular Malformations}

Studies have shown that BAV not only occurs as an isolated cardiovascular malformation (CVM) but is also associated with other CVMs. The occurrence of additional CVMs in association with BAV is 
not unexpected and implies potential valve malformation by deficient valvulogenesis or by dysplasia of other cardiovascular system elements. Other CVMs like ventricle septum failure, aortic isthmus stenosis, hypoplastic left heart syndrome, abnormal mitral valve, aortic root dilatation, and tetralogy of Fallot were found to be related to BAV. Following is a description of four of the most important genetically inheritable diseases or syndromes showing CVMs along with their characteristic presenting symptoms. It comprises the heart, the valve, and aortic arch malformations along with the above-mentioned ones [11].

\section{Fallot Tetralogy}

The Fallot tetralogy was first described in 1988 by the French physician Etienne Fallot and accounts for $10 \%$ of all congenital heart defects. It consists of a combination of the following four components: pulmonary stenosis, ventricular septum defect, right ventricular hypertrophy, and rightward displacement of the aorta, which "rides" over the ventricular septal defect and receives blood from both ventricles. Presumably, this malformation results from a misalignment of the aorticopulmonary septum, which separates the bulbous cordis from the truncus arteriosus to the ventral side during embryonic development. In this way, the aorticopulmonary septum fails to fuse with the ventricular septum. The bulbus cordis develops in to the conus arteriosus, which corresponds to the funnel-shaped portion of the outflow path of the right heart, and opens into the pulmonary trunk. The truncus arteriosus, on the other hand, is the distal part of the heart-tube, from which the root of the ascending aorta and the pulmonary artery develop in the later stages of differentiation. The cause of this malformation of the heart appears to be an autosomal aberration or a heterozygous microdeletion on the long arm of the chromosome 22 (22q11), which is autosomal dominant [12].

\section{Turner's Syndrome}

Turner syndrome (or Ullrich-Turner's syndrome or monosomy $\mathrm{X}$ ) is a chromosomal abnormality because of X-chromosomal aberration. This was discovered by Henry Turner in 1938, it occurs exclusively in women and girls who have only one functional X-chromosome instead of the usual two. The genetic changes in Turner syndrome include Xchromosomal aberration, partial detection of X-chromosome, or $\mathrm{X}$ chromosome mosaicism. Turner syndrome affects approximately 1:2,500 female births and presents with clinical features of neonatal gonadal insufficiency. However, many other organ systems can also be affected. For example, dilated cardiomyopathy (21\%), a deficiency of the pulmonary veins $(2.9 \%)$, aortic valve disorders (stenosis and/or insufficiency, 5\%), an aortic isthmus stenosis (4.4\%), or a bicuspid aortic valve $(14.7 \%)[13,14]$.

\section{Di-George's Syndrome}

The Di-George syndrome occurs with a frequency of 1:20,000 births and has a very complex disease pattern, which is attributed to a deletion on the band 11 of the long arm of the chromosome 22 in $85 \%$ to $90 \%$ of the patients. A deletion or a group of microdeletions on chromosome 22 is a quite common genetic defect and presents with varied disease patterns once described as separate conditions like the velocardiofacial syndrome or the conotruncal anomaly face syndrome. In summary, all these disease patterns are collectively referred as the "chromosome 22q11 deletion" syndrome. Despite the wide range of phenotypic malformations of the "chromosome 22q11 deletion" syndrome, some particularly key features or findings can be highlighted: congenital heart defects, facial dysmorphias, palate abnormalities, and psychomotor and linguistic developmental degeneration. The DiGeorge syndrome itself was first described in 1965 by DiGeorge, who was the first to establish a link between thymus hypoplasia; T-cell mediated immune deficiency, congenital hypoparathyroidism with hypocalcemia, and mild facial dysmorphias. The cardiac defects that are classically associated with this syndrome include the "Konotrunkalen defect". This includes defects that affect the right or left ventricular tract or large arteries, an interrupted aortic arch, Fallot's tetralogy, truncus arteriosus communis, and a ventricular septal defect [15-17].

\section{Marfan's Syndrome}

Marfan syndrome is one of the genetic connective tissue disorders first described by the French pediatrician Antonin Marfan in 1896. Marfan's disease is caused by mutations in the fibrillin- 1 gene on chromosome 15, which is an important component of the structure of the microfibrils. The basic framework of the elastic fibers of the human connective tissue is formed by these microfibrils and is found almost throughout the entire body. Because connective tissue is found throughout the body, disorders associated with this defect can affect different part of body. The main symptoms of Marfan syndrome are long limbs and increased body length, myopia, retinal detachment, aortic aneurysms, overstretch joints, narrow jaws with crooked teeth, funnel or keel breasts, changes in the spine (e.g., scoliosis). This autosomal dominant inherited syndrome occurs with frequency of 1:10,000. However, spontaneous mutations are often found. The enlargement of the aorta can extend proximally till the aortic valve resulting in, aortic insufficiency. Individuals with Marfan's syndrome can also have instable valve apparatus that result in the falling of the mitral valve into the left atrium during a systole causing a condition known as mitral valve prolapse [18-23].

\section{Genes Associated With the BAV}

Despite intensive research in the field of genetics, the genetic basis of BAV remains poorly understood. In a study by Huntington et al., $9.1 \%$ of first degree relatives of an individual with a BAV had BAV themselves, and the distribution within families was compatible with an autosomal dominant pattern of inheritance with reduced penetrance. Another study of 309 probands with BAV and their relatives detected a BAV prevalence of $24 \%$ in this group and an estimated heritability of $89 \%$. To date, it has not been possible to explain the wide spectrum of BAV manifestation by a single gene defect, which indicates that BAV is most likely a complex and heterogeneous disease. Mutations in the signaling and transcriptional regulator NOTCH1, part of the Notch signaling pathway, which is a highly conserved cell signaling system caused BAV and severe aortic valve calcification in two families but only occurs in approximately $4 \%$ of sporadic cases. Other studies, have detected mutations in NOTCH1 in BAV-associated aortopathy. Family-based linkage analysis has revealed three loci on chromosomes $18 \mathrm{q}, 5 \mathrm{q}$, and $13 \mathrm{q}$ responsible for $\mathrm{BAV}$, but no gene was identified, whereas a computational approach identified single nucleotide polymorphisms (SNPs) within the AXIN1PDIA2 locus, the endoglin gene, and on chromosome 3 using a genome-wide SNP data set. Data from animal models provide additional insight into the pathogenesis of BAV. Mice deficient in the nitric oxide generating enzyme eNOS demonstrate a high frequency of $\mathrm{R}-\mathrm{N}$ type BAV. Deletion of the zinc finger protein GATA5 results in a 
Page 3 of 4

$25 \%$ incidence of R-N type BAV in transgenic mice. Mice with heterozygous mutations in the cardiac homeobox gene NKX2-5 (NK2 Homeobox 5), which encodes a homeobox-containing transcription factor involved in heart formation and development, and mice deficient in homeobox gene HOXA1 (Homeobox A1), which is involved in protein regulation during embryologic development, developed BAVs as part of several severe cardiac malformations. The heterozygous loss of Fgf8 and GATA5 in mice predisposes them to the development of BAV. Tissue-specific deletion of the gene encoding activin receptor type 1 (Alk2/Acvr1) in the cushion mesenchyme is observed to result in the formation of aortic valve defects including BAV. Furthermore, the expression of the ubiquitin fusion degradation protein 1 homolog (UFD1L) gene and production of the according protein, which play a role in the cardiac outflow tract formation during embryogenesis, are down-regulated in BAV tissue; however, no relevant mutations in UFD1L gene were detected. Other studies observed the involvement of microRNAs (miRNAs) in BAV disease. The miRNAs are small, approximately 22 nucleotides in length, noncoding nucleotide RNAs and have been shown to modulate mRNA stability and translation. Nigam et al. demonstrated that miR-26a was down-regulated in fused aortic valve. The miR-26a was also found to be down-regulated in aneurysms. However, the exact genetic cause of BAV remains unknown. Though, BAV not only contributes considerably to cardiovascular health risks but also represents a technical challenge in cardiac valve operations. More than $50 \%$ of patients with BAV also suffer from a dilatation of the ascending aorta. In general, BAV is a technical challenge in heart valve operations relating to the question of how this malformation and associated ascending aortic diseases can be optimally corrected so the physiological properties can be preserved or imitated. Therefore, it is also rational to think about the management of associated complications of the ascending aorta. Untreated aortic aneurysm constitutes a life-threatening emergency and causes death by dilation and rupture [6,24-34].

Familial thoracic aortic aneurysms and dissections have also been associated with coarctation of the aorta, bicuspid aortic valve and aortic root dilation. Several genes and loci are known to be associated with familial TAAD (e.g. transforming growth factor beta receptor type I and receptor type II, smooth muscle-specific myosin heavy chain, smooth muscle-specific alpha-actin, myosin light chain kinase [35-40], the family of mothers against decapentaplegic homolog (SMADs) [41-43].

\section{Conclusion and Outlook}

In daily clinical practice, the operative criteria are always seriously and controversially debated. Surgical treatments are primarily carried out in case of serious causality. In young adults, a high priority was attached to valve-sparing procedures or procedures that could stabilize aortic root distensibility, leading to best valve functions to maintain smooth hemodynamics. Therefore, remodeling of the aortic root with supravalvular annuloplasty, described by Yacoub and re-implantation of aortic valves with sub- and supra-valvular annuloplasty described by David play an essential role. Each method presents its own advantages and limitation in clinical practice. Based on the technical importance of both methods, a hybrid operative procedure such as remodeling with an external subvalvular aortic ring annuloplasty could be suggested. However, prophylactic surgical methods for dilated ascending aorta are discussed only in patients whose aortic dimensions are close to pathological reference. Because of varied morphological, biomechanical patterns in BAV and BAV aortopathy, special therapeutic strategies for prophylaxis are decided based on clinical presentation and targeted follow-ups.

\section{Acknowledgements}

The author would like to acknowledge and thank the Leducq Fondation for supporting our work and giving us the opportunity to study BAV aortopathy (MIBAVA) over the coming years.

\section{References}

1. Yamagishi H, Garg V, Matsuoka R, Thomas T, Srivastava D (1999) A molecular pathway revealing a genetic basis for human cardiac and craniofacial defects. Science 283: 1158-1161.

2. Srivastava D, Cserjesi P, Olson EN (1995) A subclass of bHLH proteins required for cardiac morphogenesis. Science. 270: 1995-1999.

3. Poelmann RE, Gittenberger-De Groot AC (2008) Cardiac development. Scientific World Journal 8: 855-858.

4. Bartelings MM, Gittenberger-de Groot AC (1991) Morphogenetic considerations on congenital malformations of the outflow tract. Part 1: Common arterial trunk and tetralogy of Fallot. Int J Cardiol 32: 213-230.

5. Bartelings MM, Gittenberger-de Groot AC (1991) Morphogenetic considerations on congenital malformations of the outflow tract. Part 2: complete transposition of the great arteries and double outlet right ventricle. Int J Cardiol. 33: 5-26.

6. Garg V, Muth AN, Ransom JF, Schluterman MK, Barnes R, et al. (2005) Mutations in NOTCH1 cause aortic valve disease. Nature. 437: 270-274.

7. Gittenberger-de Groot AC, Bartelings MM, Deruiter MC, Poelmann RE (2005) Basics of cardiac development for the understanding of congenital heart malformations. Pediatric research. 57: 169-176.

8. Noden DM, Poelmann RE, Gittenberger-De Groot AC (1995) Cell origins and tissue boundaries during outflow tract development. Trends Cardiovasc Med. 5: 69-75.

9. Mohamed SA, Sievers HH (2011) Ascending aneurysms in bicuspid aortic valve. In: Grundmann RT, (ed). Diagnosis and treatment of abdominal and thoracic aortic aneurysms including the ascending aorta and aortic arch. Rijeka: INTECH Open Access Publisher. 161-174.

10. Kirby ML, Waldo KL (1995) Neural crest and cardiovascular patterning. Circulation Research 77: 211-215.

11. Lalani SR, Belmont JW (2014) Genetic basis of congenital cardiovascular malformations. Eur J Med Genet 57: 402-413.

12. Hoffman JI, Kaplan S (2002) The incidence of congenital heart disease. J Am Coll Cardiol 39: 1890-1900.

13. Sybert VP, McCauley E (2004) Turner's syndrome. N Engl J Med 351: 1227-1238.

14. Elsheikh M, Dunger DB, Conway GS, Wass JA (2002) Turner's syndrome in adulthood. Endocrine Reviews 23: 120-140.

15. Wilson DI, Burn J, Scambler P, Goodship J (1993) DiGeorge syndrome: Part of CATCH 22. J Med Genet 30:852-856.

16. Sullivan KE (2008) Chromosome 22q11. 2 deletion syndrome: DiGeorge syndrome/velocardiofacial syndrome. Immunol Allergy Clin North Am 28: 353-366.

17. McDonald-McGinn DM, Sullivan KE (2011) Chromosome 22q11. 2 deletion syndrome (DiGeorge syndrome/velocardiofacial syndrome). Medicine 90: 1-8.

18. Dietz HC, Cutting GR (1991) Marfan syndrome caused by a recurrent de novo missense mutation in the fibrillin gene. Nature 352: 337-339.

19. Dietz HC, McIntosh I, Sakai LY, Corson GM, Chalberg SC, et al. (1993) Four novel FBN1 mutations: significance for mutant transcript level and EGF-like domain calcium binding in the pathogenesis of Marfan syndrome. Genomics. 17: 468-475. 
Citation: Mohamed SA (2017) Heart, Aorta and Aortic Valve Development and Cardiovascular Malformations. Human Genet Embryol 7: 139. doi:10.4172/2161-0436.1000139

Page 4 of 4

20. Dietz HC, Pyeritz RE (1995) Mutations in the human gene for fibrillin-1 (FBN1) in the Marfan syndrome and related disorders. Human Molecular Genetics. 4: 1799-1809.

21. Dietz HC (1994) New insights into the genetic basis of aortic aneurysms. Monogr Pathol. 37: 144-155.

22. Dietz HC, Loeys B, Carta L, Ramirez F (2005) Recent progress towards a molecular understanding of Marfan syndrome. In Am J Med Genet Part C: Seminars in Medical Genetics. Wiley Subscription Services, Inc., A Wiley Company 139: 4-9.

23. Loeys BL, Schwarze U, Holm T, Callewaert BL, Thomas GH, et al. (2006) Aneurysm syndromes caused by mutations in the TGF- $\beta$ receptor. $N$ Engl J Med. 355: 788-798.

24. Roberts WC (1970) The congenitally bicuspid aortic valve: a study of 85 autopsy cases. Am J Cardiol 26: 72-83.

25. Cripe L, Andelfinger G, Martin LJ, Shooner K, Benson DW (2004) Bicuspid aortic valve is heritable. J Am Coll Cardiol 44: 138-143.

26. Huntington K, Hunter AG, Chan KL (1997) A prospective study to assess the frequency of familial clustering of congenital bicuspid aortic valve. J Am Coll Cardiol 30: 1809-1812.

27. Ward C (2000) Clinical significance of the bicuspid aortic valve. Heart 83 81-85.

28. Laforest B, Andelfinger G, Nemer M (2001) Loss of Gata5 in mice leads to bicuspid aortic valve. J Clin Invest 121: 2876-2887.

29. Lee TC, Zhao YD, Courtman DW, Stewart DJ (2000) Abnormal aortic valve development in mice lacking endothelial nitric oxide synthase. Circulation 101:2345-2348.

30. Wessels MW, Berger RM, Frohn-Mulder IM, Roos-Hesselink JW, Hoogeboom JJ, et al. (2005) Autosomal dominant inheritance of left ventricular outflow tract obstruction. Am J Med Genet A 134: 171-179.

31. Miller MJ, Geffner ME, Lippe BM, Itami RM, Kaplan SA, et al. (1983) Echocardiography reveals a high incidence of bicuspid aortic valve in Turner syndrome. J Pediatr 102: 47-50.

32. Andelfinger G, Tapper AR, Welch RC, Vanoye CG, George AL, et al. (2002) KCNJ2 mutation results in Andersen syndrome with sex-specific cardiac and skeletal muscle phenotypes. Am J Hum Genet 71: 663-668.

33. Wooten EC, Iyer LK, Montefusco MC, Hedgepeth AK, Payne DD, et al. (2010) Application of gene network analysis techniques identify AXIN1/
PDIA2 and endoglin haplotypes associated with bicuspid aortic valve. PLoS One. 5: e8830.

34. Mohamed SA (2017) Genetic basis and hemodynamic aortopathy of the ascending aorta and dissection: Cardiac surgery. Avid Science 2-39.

35. Guo D, Hasham S, Kuang SQ, Vaughan CJ, Boerwinkle E, et al. (2001) Familial thoracic aortic aneurysms and dissections: genetic heterogeneity with a major locus mapping to 5q13-14. Circulation 103: 2461-2468.

36. Pearson GD, Devereux R, Loeys B, Maslen C, Milewicz D, et al. (2008) Report of the National Heart, Lung, and Blood Institute and National Marfan Foundation Working Group on research in Marfan syndrome and related disorders. Circulation 118: 785-791.

37. Milewicz DM, Guo DC, Tran-Fadulu V, Lafont AL, Papke CL, et al. (2008) Genetic basis of thoracic aortic aneurysms and dissections: focus on smooth muscle cell contractile dysfunction. Annu Rev Genomics Hum Genet 9: 283-302.

38. Kroner BL, Tolunay HE, Basson CT, Pyeritz RE, Holmes KW, et al. (2011) The National Registry of Genetically Triggered Thoracic Aortic Aneurysms and Cardiovascular Conditions (GenTAC): results from phase I and scientific opportunities in phase II. Am Heart J 162: 627-632.

39. Mendoza DD, Kochar M, Devereux RB, Basson CT, Min JK, et al. (2011) Impact of image analysis methodology on diagnostic and surgical classification of patients with thoracic aortic aneurysms. Ann Thorac Surg 92: 904-912.

40. Guo DC, Papke CL, Tran-Fadulu V, Regalado ES, Avidan N, et al. (2009) Mutations in smooth muscle alpha-actin (ACTA2) cause coronary artery disease, stroke, and Moyamoya disease, along with thoracic aortic disease. Am J Hum Genet 84: 617-627.

41. Micha D, Guo DC, Hilhorst-Hofstee Y, Van KF, Atmaja D, et al. (2015) SMAD2 Mutations are associated with arterial aneurysms and dissections. Hum Mutat 36: 1145-1149.

42. Van de Laar IM, Oldenburg RA, Pals G, Roos-Hesselink JW, De Graaf BM, et al. (2011) Mutations in SMAD3 cause a syndromic form of aortic aneurysms and dissections with early-onset osteoarthritis. Nat Genet 43: 121-126.

43. Tan HL, Glen E, Topf A, Hall D, O'Sullivan JJ, et al. (2012) Nonsynonymous variants in the SMAD6 gene predispose to congenital cardiovascular malformation. Hum Mutat 33: 720-727. 